\title{
Discussion on College Students' Psychological Counseling Based on Fuzzy Definition of the Relationship between Trust and Help-seeking Willingness
}

\author{
Youli Kang \\ Counseling Service, Vocational and Technical College, China West Normal University, Nanchong, \\ 637000, China
}

Keywords: College students. Psychological help-seeking. Psychological counseling. Trust

\begin{abstract}
In recent years, college students who are between the society and schools have increasing psychological pressure. With growing strong negative pressure such as learning pressure, employment pressure and life pressure etc, lots of college students begin to have personal emotion of unwillingness to trust people and things around. Such emotion is generated along with a variety of adverse psychological problems. The author finds several groups of findings of experiment on psychological help-seeking of college students in different regions from psychological data, and infers and discusses through these findings. In such a rigorous social context, some of contemporary college students deal with their own psychological problems by measures such as avoidance, indifference and deliberate refusal etc because of generally low trust to others.
\end{abstract}

\section{Introduction}

Generally, everyone has more or less some psychological deficiencies. In today's context of increasing fast pace of life, people face increasingly more pressure and events every day. Lots of situations may lead to people's psychological help-seeking, such as a natural disaster, death of a relative, failure in an examination and breaking up etc. People will have different reactions in these cases. It is psychologically called psychological stress reaction. Due to social environment, lots of people would easily close their psychology after having experienced a lot in social life. The most direct expression is that they would not trust anyone except themselves. Younger social groups which mainly include college students become major bearers of psychological problems.

\section{Analysis of college students' psychological help-seeking}

\section{Objects of college students' psychological help-seeking}

Social individuals would turn to other groups or individuals for help or comfort when encountering troubles and pressure in psychology and personal emotions etc, and thus solve psychological pressure and difficulties. Actually, in terms of psychological social significance, there are two categories of objects to which individuals could turn for talking and help. The first category is professionals, such as psychologists, psychological guiders and psychological counselors etc. They would adjust patients' psychological trauma with professional knowledge and treatment methods from a psychological professional perspective. Another category is non-professionals, i.e. groups that individuals feel close and trust, such as lovers, parents and friends etc. Findings of our experiment indicate that most college students would basically talk to and tell non-professionals about their psychological problems after the experiment, while having attitudes of suspicion, unwillingness and ignorance etc towards professionals. This also reflects decreasing trust of college students.

\section{Tendency of college students’ psychological help-seeking}

In this regard, college students have almost the same reactions according to experimental findings. Individuals under experiment hope to solve psychological problems with their own strength at the beginning. In terms of trust, this indicates that college students rely on themselves the most. Basically, all individuals would try to solve psychological problems on their own. None of them would seek help from others directly at the beginning. The majority of them would choose non-professionals as 
helpers, i.e. relatives and friends. Very few of them choose professional psychologists to help them solve psychological problems. Then, degree of trust is reflected. They choose non-professionals as they trust them far more than professionals. Male students, who have very rigid gender concepts and more conflicts, show more resistance towards help of professionals. Our experimental survey also finds that college students from rural areas have a relative lack of psychological knowledge and recognition, and those from urban areas are generally more prone to exchanges of psychological help-seeking etc than rural ones.

\section{Reasons that affect willingness of psychological help-seeking}

\section{Demographic variables}

In experimental data, elder college students mostly refuse to communicate with strangers or professionals. When asked about reasons, nearly half of them choose "other students of my age do not see a psychologist”. Similarly, younger students choose professionals for psychological counseling, mainly because "students of my age choose to check psychological problems in professional hospitals".

So, among college students and individuals, personal "identity" will be established due to similarities. Such identity mainly includes age, status, identity, degree and personality etc. Seeing students of the same age face their own psychological help-seeking willingness actively, other students with the same identity also choose to receive psychological counseling and help.

\section{Personal traits of college students}

The so-called personal traits are personal personalities of experimental individuals, and are divided into three categories namely social traits, physiological traits and psychological traits. Individuals' psychological traits are mainly concerned in experiment. Whether a college student is willing to face his/her own psychological help-seeking willingness sincerely depends on his/her psychological traits to a great extent. As experimental individuals, college students are normal human beings with psychological traits. However, everyone has not the same psychological traits. Psychological traits mainly have the following four influencing factors.

\section{Emotional processing capability}

Individuals' emotional processing capability lies in whether they could recognize correctly that they have psychological help-seeking willingness. This is perception ability of processing capability. Psychologically, the lower perception ability that college students have, the more unwilling they would receive psychological counseling. They would not admit their psychological help-seeking willingness. On the contrary, college students who receive psychological counseling and examine their inner help-seeking willingness generally have higher emotional processing capability, as they are willing to face up to themselves and use all available resources to stabilize and correct their emotions. They would not refuse beneficial help, as they know that correct emotional processing is favorable.

\section{A sense of personal emotional control}

In experimental data, comparison has been made between college students who seek actively professional psychologists for counseling and those who have had psychological counseling with professionals, and a simple survey and statistics of psychological conditions are conducted. Results indicate that people with a higher sense of personal emotional control would not have psychological help-seeking easily, as they have very good self-regulation ability. College students who receive psychological counseling often have not a strong sense of self-control. Because of difference in personalities, a sense of emotional control becomes an important cause of whether they choose to receive psychological counseling or not. However, such a sense of emotional control is not a decisive factor of good or bad psychological traits. Control level is gradually formed because of different personal experience.

\section{Treatment fear of psychological problems}

Treatment fear academically refers to negative emotions generated at the beginning before psychological counseling or treatment effects, and leads to weakening help-seeking willingness. 
College students have lower trust to professionals at the beginning, and such subjective assumption is not positive and is a mental state in hesitation between desire and refusal. We also get another group of experimental findings: among college students, those who have received psychological counseling before have far lower treatment fear for another psychological counseling than those who have never received. This also indicates that past counseling and treatment experience is conducive to overcoming college students' treatment fear, and this experience can help them discover their own psychological problems and increase trust to professionals.

Besides personal experience of psychological counseling, we also summarize another six reasons of treatment fear through experiment, including:

(1) Fear of embarrassment caused by help-seeking willingness

(2) Unwilling to change current situation

(3) Have fixed ideas about psychological counseling and treatment

(4) Misjudgment due to psychological counseling seen before

(5) Resistance towards stimulating questions in psychological counseling

(6) Fear brought by social pressure and prejudices

\section{Discussion on current situation of college students' help-seeking willingness}

\section{Current situation of experimental objects of college students}

For overall performance of college students, most of them have normal help-seeking willingness when encountering psychological troubles. When help-seeking willingness reaches a certain degree, $65 \%$ of college students would turn to others if they could not solve by themselves. The rest mostly deal with psychological problems through sports or self-entertainment activities.

In psychological researches, people, who have psychological help-seeking willingness of seeking others' help or solving by themselves (including sports, reading and entertainment etc), have a positive psychological responding model, while people, who retreat, escape or refuse to respond in front of psychological help-seeking willingness, have a negative responding model. In the experiment, about 1/4 of college students choose retreat responding model, and their psychology tends more to be let it be, and are mostly introverted and love to stay alone in daily life, and their psychological state would sometimes be negative such as low, disappointment, depression and suspicion etc. So, to carry out educational psychological counseling, communication with and popularization among these people shall be strengthened, in order to make them more positive and initiative in psychological help-seeking willingness.

\section{Discussion on identity difference of experimental objects}

For psychological help-seeking willingness, female college students are more willing to seek others' help than males ones, and are more active to seek psychological counseling of professionals. When encountering psychological help-seeking, many male students would choose active responding model of the abovementioned sports and self-entertainment etc. It shall be noted that the majority of male students choose to stay alone and refuse to face psychological problems.

\section{Social status that affects college students' psychological help-seeking}

College students' psychological help-seeking is mainly because of pressure in real life, as they have social attribute. Each person has different social identities, and receives different influence from their families. Intensity of help-seeking willingness occurred in psychology is also related to cultures of countries, cities and schools etc in which students live.

\section{Conclusions}

There are many factors that affect psychology of contemporary college students, and these factors mainly include unsmooth college life and approaching social pressure. Help-seeking willingness occurs when both unsmooth college life and approaching social pressure accumulate to a certain degree. For college students in different social and cultural contexts, besides the most fundamental trust problem, a lot of other factors have impacts on them to make choice in help-seeking willingness. 
Generally, college students would actively talk to others and seek help in front of help-seeking willingness, but a small number of them choose negative responding ways because of various reasons. All these require psychological researchers to keep trying and studying on more comprehensive psychological environment and psychological problems of college students in modern society.

\section{References}

[1] Xie Tanghong: Investigation of College Students' Attitude towards Psychological Counseling and Their Psychological Help-seeking Behaviors,Science of Social Psychology, 2011 (Z2).

[2] Zhao Li, Jiang Guangrong, Wang Ying: Relationship between College Students’ Psychological Counseling Trust and Professional Help-seeking Intention, Chinese Mental Health Journal, 2011 (04)

[3] Chen Yuwen, Wu Dongmei, Zhao Yuwei, Ma Lijun: The Research on the Students' Attitude towards Psychological Counseling,Medicine and Society, 2010 (02)

[4] Wu Jiadong, Wang Shengyong, Dong Xiaomei: Survey on Undergraduate Students' Cognition, Attitude and Behavior toward Psychological Counseling,Chinese Journal of Disease Control \& Prevention, 2010 (04)

[5] Han Jing, Wei Ping: Development and Evaluation of Attitude toward Seeking Professional Psychological Help Questionnaire of College Students,Chinese Journal of School Health, 2010 (03) 